\title{
Correlation structure of the cheek teeth enamel crown patterns in the genus Equus (Mammalia: Equidae): an analysis by geometric morphometrics with outline points
}

\begin{abstract}
Igor Ya. Pavlinov*, Natalia N. Spasskaya
ABSTRACT. Correlation structure of the cheek teeth enamel crown patterns in the genus Equus was studied by means of geometric morphometrics using outline points as descriptors to reveal the levels of morphological integration of the toothrow elements. Crown patterns in 34 upper and 31 lower toothrows (260 teeth in total) from 30 horse species were analyzed, the respective sets of 70 to 150 outline points were processed using the elliptic Fourier, principal component, and cluster analyses. The most correlated were shown to be the serial homologous crown elements within premolar and molar toothrow portions and less across the total toothrow. Correlation between occluding upper and lower teeth was shown to be low. Such correlation structure allowed identifying several levels of integration of the cheek teeth crown patterns in the genus Equus. A possibility of considering the serial homologous crown elements as the modules of the evolutionary developmental structure of the equine toothrows was discussed. Certain perspectives of similar studies in the specialized artiodactyles were emphasized.
\end{abstract}

How to cite this article: Pavlinov I.Ya., Spasskaya N.N. 2021. Correlation structure of the cheek teeth enamel crown patterns in the genus Equus (Mammalia: Equidae): an analysis by geometric morphometrics with outline points // Russian J. Theriol. Vol.20. No.1. P.70-81. doi: 10.15298/rusjtheriol.20.1.08.

KEY WORDS: dentition, geometric morphometrics, outline points, Equus, levels of integration, evo-devo.

\section{Корреляционная структура эмалевых элементов коронки щечных зубов в роде Equus (Mammalia: Equidae): геометрическая морфометрия с использованием контурных точек}

\section{И.Я. Павлинов*, Н.Н. Спасская}

РЕЗЮМЕ. Корреляционная структура эмалевых элементов коронки щечных зубов у представителей рода Equus изучалась с помощью геометрической морфометрии с использованием контурных точек для выявления уровней морфологической интеграции элементов зубных рядов. Проанализированы коронки 34 верхних и 31 нижних зубных рядов (всего 260 зубов) у 30 видов лошадей, разные элементы зубной коронки описывали совокупностью от 70 до 150 контурных точек, данные по ними были обработаны с использованием методов эллиптических преобразований Фурье, анализа главных компонент и кластерного анализа. Показано, что наиболее скоррелированными являются сериальные гомологичные элементы коронки в пределах премолярного и молярного отделов, в меньшей степени - всего зубного ряда. Корреляция между верхними и нижними окклюдирующими зубами оказалась низкой. Такая корреляционная структура позволила выделить несколько уровней интеграции элементов коронки щечных зубов у представителей рода Equus. Обсуждается возможность рассмотрения сериальных гомологичных элементов коронки как модулей эволюционного развития зубов у лошадей. Подчеркнуты перспективы подобных исследований у специализированных парнокопытных.

КЛЮЧЕВЫЕ СЛОВА: зубы, геометрическая морфометрия, контурные точки, Equиs, уровни интеграции, эво-дево.

* Corresponding author 


\section{Introduction}

In considering organization and functioning of the complex morphological systems, one of the key issues is the existence of different levels of morphological integration in them (Olson \& Miller, 1958; Cheverud, 1982, 1995; Bolker, 2000; Schlosser \& Wagner, 2004; Callebaut \& Rasskin-Gutman, 2005; Klingenberg, 2008a, 2014). In recent time, the whole problem of the levels of morphological integration is considered within the framework of the fundamental evo-devo concept (Bolker, 2000; Schlosser \& Wagner, 2004; Callebaut \& Rasskin-Gutman, 2005). However, genetic studies presumed by the latter are available on a very limited number of the model species; therefore, research of the morphological integration at a phenomenological level based on comparative analysis of morphometric data remains of key importance (Klingenberg, 2014). The studies of this kind that are based on advanced numerical methods revealed specific conceptual and methodological problems, which awareness and solution require accumulation of a large amount of comparative data (Callebaut \& Rasskin-Gutman, 2005; Hallgrímsson et al., 2009; Mitteroecker \& Gunz, 2009; Goswami \& Polly, 2010; Klingenberg, 2014).

The mammalian dentition is among the most popular objects of research on the levels of morphological integration. In this vein, the dentition of carnivores, primates, some rodents, and insectivores were most actively studied (Gould \& Garwood, 1969; Gingerich \& Winkler, 1979; Cochard, 1981; Pengilly, 1984; Dayan et al., 2002; Pavlinov et al., 2008a; Laffont et al., 2009; Renaud et al., 2009; Labonne et al., 2014; etc.). For many of them, a rather clear differentiation of dentition into certain compartments corresponding mainly to the homology groups (bilateral elements of the dentition, premolar and molar portions of the toothrow, etc.), as well as to the functional groups within the same homology group, was shown. However, ungulates with their specific dentition have remained out of attention so far. Meanwhile, the study of the horses showed that the correlation structure of their dentition was very peculiar: the entire toothrow appeared to be a highly integrated whole in which individual teeth could not be identified as separate units (Spasskaya \& Pavlinov, 2008).

The methodology of quantitative analysis of the levels of morphological integration is traditionally based on the correlation analysis supplemented by cluster and principal component analyses (Olson \& Miller, 1958; Berg, 1960; Van Valen, 1965; Cochard, 1981; Cheverud, 1982, 1995; Cheverud et al., 1989; Murren, 2002; Rostova, 2002; Magwene, 2008; Pavlinov et al., 2008a; Pavlicev et al., 2009; Goswami \& Polly, 2010). Within this approach, the correlation structure of a complex morphological object is interpreted as a reflection of the levels of morphological integration of its elements. For a "quasi-statistical" estimation of the validity of the levels of integration thus identified, nonparametric randomization methods of the original data are now most often applied, such as subsampling and bootstrapping
(Cheverud et al., 1989; Pavlinov et al., 2008a; Goswami \& Polly, 2010).

For the purpose of correlation analysis, the morphological objects were traditionally characterized by linear measurements; recently, no less popular became describing such systems by means of the geometric morphometrics (Cardini, 2003; Navarro et al., 2004; Monteiro et al., 2005; Goswami, 2006; Klingenberg, 2009; Laffont et al., 2009; Renaud et al., 2009; Zelditch et al., 2009, Goswami \& Polly, 2010; Ledevin et al., 2010; Labonne et al., 2014). The latter is attractive because it allows working with the shape of morphological objects in its "pure form" excluding the effect of size differences (Bookstein, 1991; Pavlinov \& Mikeshina, 2002; Zelditch et al., 2012; Vasil'ev et al., 2018).

Research on the horse dental variation based on geometric morphometrics is just beginning, and it was based on analyses of separate teeth and employing semilandmarks to describe dental crown elements (Seetah et al., 2016; Barrón-Ortiz et al., 2017; Cucchi et al., 2017; Heck et al., 2018). A distinctive feature of our work is that (a) almost complete rows of the cheek teeth were examined and (b) configuration of the dental crown pattern was described using outline points. The latter allows describing dental crown pattern in quite a detailed manner and, unlike semi-landmarks used in a number of similar works (Barrón-Ortiz et al., 2017; Cucchi et al., 2017; Chuang \& Bonhomme, 2019), does not request strict fixation of several reference landmarks along the contour line that has no unambiguously homologized points (Bookstein, 1997; Klingenberg, 2008b), as in the case of the enamel layers on the flat chewing surface of the horse check teeth.

Provided herewith are the results of our analysis of the correlation structure of the cheek teeth crown patterns in the genus Equus based on geometric morphometrics with the outline points. The principal working hypothesis to be tested in our study was the existence of various levels of integration of the cheek teeth enamel crown patterns in the genus Equus. Because of the scanty of our materials, we did not intend to consider the diversity of correlation patterns of the crown elements among equine species and to discuss their possible causes. With this, the main purpose of this paper is to demonstrate possible prospects of the methodological approach applied herein in revealing the levels of integration of the dental crown patterns in the equines.

\section{Materials and methods}

Following the general objective of our study, the sample was composed with observing two main criteria: (a) the coverage of the Equus species diversity should be as wide as possible, including both extant and extinct species, and (b) it was necessary to examine the (nearly) complete upper and lower toothrows instead of isolated teeth. These criteria are somewhat incompatible, as the use of fossil materials (1st criterion) limits significantly a possibility of studying complete dentitions (2nd 
criterion). As a result, it appeared possible to include in our sample 34 upper and 31 lower toothrows from 58 specimens belonging to 30 species of the genus Equus (see Appendix); in total, 260 teeth were analysed. Most of the specimens were represented by photographs and drawings borrowed from various publications, their sources are indicated in the Appendix; they were supplemented by photographs of the dentitions of the specimens in the collection of the Zoological Museum of Moscow State University (ZMMU). The sample included specimens with medium-worn teeth corresponding to the individual age of 5 to 10 years based on standard criteria (Dyurst, 1936). We deliberately did not limit the composition of our sample to the specimens with equally slightly tooth wear, supposing that similar or different wear patterns on the teeth at different wear stages (safe for the most worn ones) can provide an important biologically meaningful information about the correlation structure of their crown patterns.

Our study was based on a comparison of the enamel crown patterns of the 3rd and 4th premolars and the 1 st and 2nd molars in the upper and lower toothrows. The following basic crown elements were analyzed: (a) general enamel outline of the entire crown of each of the upper teeth, (b) the same of each of the lower teeth, (c) enamel outlines of each of the prefossettes and (d) of the postfossettes on each of the upper teeth (Fig. 1). Different (not always good enough) quality of the teeth images borrowed from different sources excluded a possibility of applying the method of tracing the enamel structure with an optical equipment used in some studies (Barrón-Ortiz et al., 2017; Cucchi et al., 2017). So, the general scheme of describing these elements was as follows. The basic elements of the enamel crown pattern were outlined manually based on the teeth images in the CorelDraw using the Shape tool. Closed vector lines of a minimum thickness were drawn along the midline of the enamel outlines. The resulting lines were converted into halftone raster images to represent the basic crown elements to be compared. In the subsamples ready for the subsequent numerical processing, each of these elements was represented by a set of the outlines obtained for the individual teeth of different specimens.

Each closed outline was described by the x-ycoordinate system of the outline points set automatically equidistantly along the outline starting from an initial landmark. The latter was set at the anterior uppermost corner of the contour of the respective crown element. The number of the outline points was determined taking into consideration complexity of the enamel patterns being pointed: the general outline of each upper teeth was described by 100 points, the general outline of each lower teeth was described by 150 points, and the outline of each fossette was described by 70 points. The outline points were set using the tpsDig2 program (Rohlf, 2017) by the "Outline object" tool. These outline points were then converted into standard landmarks using the tpsUtil program (Rohlf, 2019).

For the subsequent statistical analyses, $x-y$-coordinates of the landmarks were transformed into the coefficients of the Fourier ellipses by the Elliptical Fourier Analysis (EFA), which effectiveness for describing and comparing the shapes of morphological objects including tooth crown outlines has been shown in a number of studies (Navarro et al., 2004; Renaud et al., 2009; Labonne et al., 2014; Lyakh, 2019). Its principal advantage, as compared to the relative warps analysis, is due to its providing a possibility to compare the contour

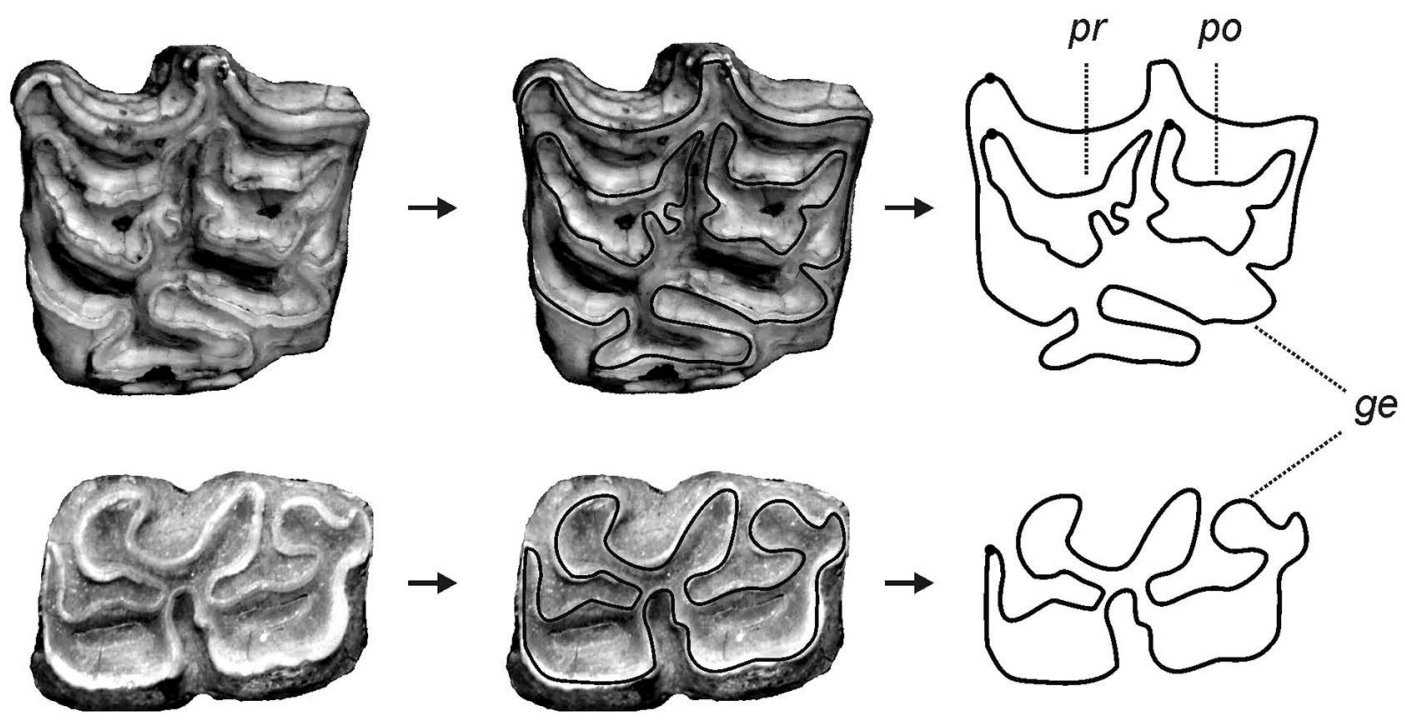

Figure 1. A flow chart of drawing outlines on the 1st upper (above) and the 1st lower (below) molar crowns in the genus Equus; $g e$ - general outline, $p o$ - postfossette, $p r$ - prefossette. Dots indicate position of the respective initial landmarks. 
lines that lack homologues landmarks and are significantly different from each other (Kuhl \& Giardina, 1982; Ferson et al., 1985; Hammer et al., 2001). For this, we used the EFA routine in the PAST program with 20 harmonics calculated (Hammer et al., 2001). For each of the dental crown elements, the principal components (PCs) were then extracted from the above coefficients, their number was determined by the number of specimens in the respective subsample. These PC values were used in all subsequent statistical analyses carried out in the programs Statistica for Windows (StatSoft, 2014) and PAST.

Because of incomplete coincidence of the subsamples for the upper and lower toothrows, statistical analyses were carried out separately for the three data blocks: (a) for the upper dentition, (b) for the lower dentition, and (c) for both dentitions belonging to the same specimens. All comparisons were based on particular specimens regardless of their taxonomic allocation.

At a preliminary stage of the numerical analyses, contribution of the age-related effect to the overall disparity of the structure of the enamel patterns was estimated using the one-way analysis of variance (ANOVA). For this, two age groups were recognized based on the dental wear, with 26 and 9 specimens for the upper and 17 and 14 specimens for the lower dentition per each of the age group, respectively. A quantitative measure of the contribution was defined as the total ratio of the sums of squares corresponding to the explained and random variances for all crown elements characterized by the 1st PC values (Pavlinov et al., 2008b; Pavlinov, 2011).

The levels of morphological integration of the toothrows were investigated using cluster and correlation analyses. Pairwise Euclidean distances were first calculated between the specimens in the respective subsample for each crown element over the entire set of PCs characterizing it. Pairwise Pearson correlation coefficients between the respective Euclidean distance matrices were calculated to evaluate their similarity in the Zt program (Bonnet \& de Peer, 2002). At the next step, standard correlation distances were calculated between the vectorized Euclidean distance matrices obtained for the crown elements, and then phenograms were produced by the Ward algorithm based on the correlation distances, with the specimen-based bootstrap estimations of the clusters support (1000 replicates). A proposal to use the subsampling method for such an estimation (Pavlinov et al., 2008; Goswami \& Polly, 2010) seemed to be hardly suitable in our case because of small size of the entire sample. These phenograms, with the crown elements distributed on them, served as graphic representations of the correlation structure and levels of integration of the toothrows.

\section{Results}

The proportion of the variance explained by the $1 \mathrm{st}$ PC varies from $23.3 \%$ to $48.3 \%$ of the entire disparity of the crown elements (Tab. 1). This proportion is on average the highest for the upper molars (41.4-44.5\%),
Table 1. The proportions of explained variance of the entire disparity of the crown elements attributed to the 1st PC

(EFA) and to the age-related differences (ANOVA) in the genus Equus.

\begin{tabular}{|l|c|c|c|}
\hline \multirow{2}{*}{ Crown elements } & \multirow{2}{*}{ 1st PC (\%) } & \multicolumn{2}{c|}{ Age differences } \\
\cline { 3 - 4 } & & $F$ & $p$ \\
\hline up_P3-1 & 41.9 & 5.15 & 0.030 \\
\hline up_P3-2 & 36.4 & 4.17 & 0.049 \\
\hline up_P3-3 & 40.9 & 0.03 & 0.855 \\
\hline up_P4-1 & 41.9 & 7.64 & 0.009 \\
\hline up_P4-2 & 35.2 & 16.62 & 0.000 \\
\hline up_P4-3 & 34.4 & 0.70 & 0.408 \\
\hline up_M1-1 & 44.2 & 0.01 & 0.913 \\
\hline up_M1-2 & 48.3 & 14.36 & 0.001 \\
\hline up_M1-3 & 40.9 & 1.12 & 0.297 \\
\hline up_M2-1 & 42.8 & 0.40 & 0.530 \\
\hline up_M2-2 & 42.5 & 8.03 & 0.007 \\
\hline up_M2-3 & 38.7 & 0.82 & 0.369 \\
\hline lo_P3-1 & 30.0 & 0.48 & 0.620 \\
\hline lo_P4-1 & 23.3 & 0.78 & 0.466 \\
\hline lo_M1-1 & 39.7 & 0.42 & 0.657 \\
\hline lo_M2-1 & 32.8 & 1.51 & 0.237 \\
\hline
\end{tabular}

Designations of the crown elements: lo - low, up - upper, $\mathrm{P}$ - premolars, $\mathrm{M}$ - molars, $1-4$ - tooth number according to its position in respective portion of the toothrow, 1 - general outline, 2 - prefossett, 3 - postfossett. For instance, P2-1 designates general outline of the $2 \mathrm{~d}$ premolar.

slightly lower for the upper premolars (34.4-41.9\%), the smaller for the lower molars $(32.8-39.7 \%)$, and especially for the lower premolars $(23.3-30.0 \%)$. As to the individual crown elements of the upper toothrow, the proportion of the variance explained by the 1 st $\mathrm{PC}$ is on average the largest for the general outlines (42.7\%) and the smallest for the postfossettes (38.8\%). Distributions of the specimens according to their PC scores for the particular crown elements showed no clear-cut patterns and is not provided here as it is irrelevant to the main task of our analysis.

Age-related differences by the 1st PC are not especially high (Tab. 1). Judging by the values of the $F$-criterion, these differences are most pronounced for the prefossettes of the 4th premolar and the 1st upper molar (the $F$-criterion is 16.6 and $14.4, p<0.001$, respectively). The proportion of the variance explained by the age differences for all crown elements is $11.6 \%$ in the upper toothrow and $5.8 \%$ in the lower toothrow. However, the sample size is too small to highlight the age-related differences in more detail.

Correlations between crown elements based on the entire set of PCs show a significant heterogeneity: the correlation coefficients between the elements vary from 0.00 to 0.68 (Tabs 2, 3). In the upper toothrow, the highest correlations are between prefossettes $(0.47-0.68)$ and postfossettes $(0.33-0.66)$, correlations between general outlines appear to be much lower $(0.00-0.18)$. Correlations 
Table 2. Correlation coefficients (absolute values) between crown elements of the upper toothrow in the genus Equus.

\begin{tabular}{|c|c|c|c|c|c|c|c|c|c|c|c|}
\hline & up_P3-1 & up_P3-2 & up_P3-3 & up_P4-1 & up_P4-2 & up_P4-3 & up_M1-1 & up_M1-2 & up_M1-3 & up_M2-1 & up_M2-2 \\
\hline up_P3-2 & 0.09 & & & & & & & & & & \\
\hline up_P3-3 & 0.02 & 0.32 & & & & & & & & & \\
\hline up_P4-1 & 0.18 & 0.02 & 0.18 & & & & & & & & \\
\hline up_P4-2 & 0.17 & 0.68 & 0.23 & 0.08 & & & & & & & \\
\hline up_P4-3 & 0.02 & 0.25 & 0.66 & 0.22 & 0.23 & & & & & & \\
\hline up_M1-1 & 0.14 & 0.07 & 0.04 & 0.04 & 0.01 & 0.05 & & & & & \\
\hline up_M1-2 & 0.17 & 0.55 & 0.20 & 0.05 & 0.39 & 0.15 & 0.01 & & & & \\
\hline up_M1-3 & 0.10 & 0.36 & 0.52 & 0.14 & 0.28 & 0.37 & 0.01 & 0.38 & & & \\
\hline up_M2-1 & 0.05 & 0.01 & 0.04 & 0.17 & 0.01 & 0.03 & 0.27 & 0.04 & 0.07 & & \\
\hline up_M2-2 & 0.13 & 0.47 & 0.29 & 0.03 & 0.51 & 0.16 & 0.06 & 0.54 & 0.33 & 0.05 & \\
\hline up_M2-3 & 0.09 & 0.27 & 0.33 & 0.04 & 0.31 & 0.21 & 0.01 & 0.31 & 0.67 & 0.01 & 0.40 \\
\hline
\end{tabular}

Note: See Table 1 for designations of the crown elements.

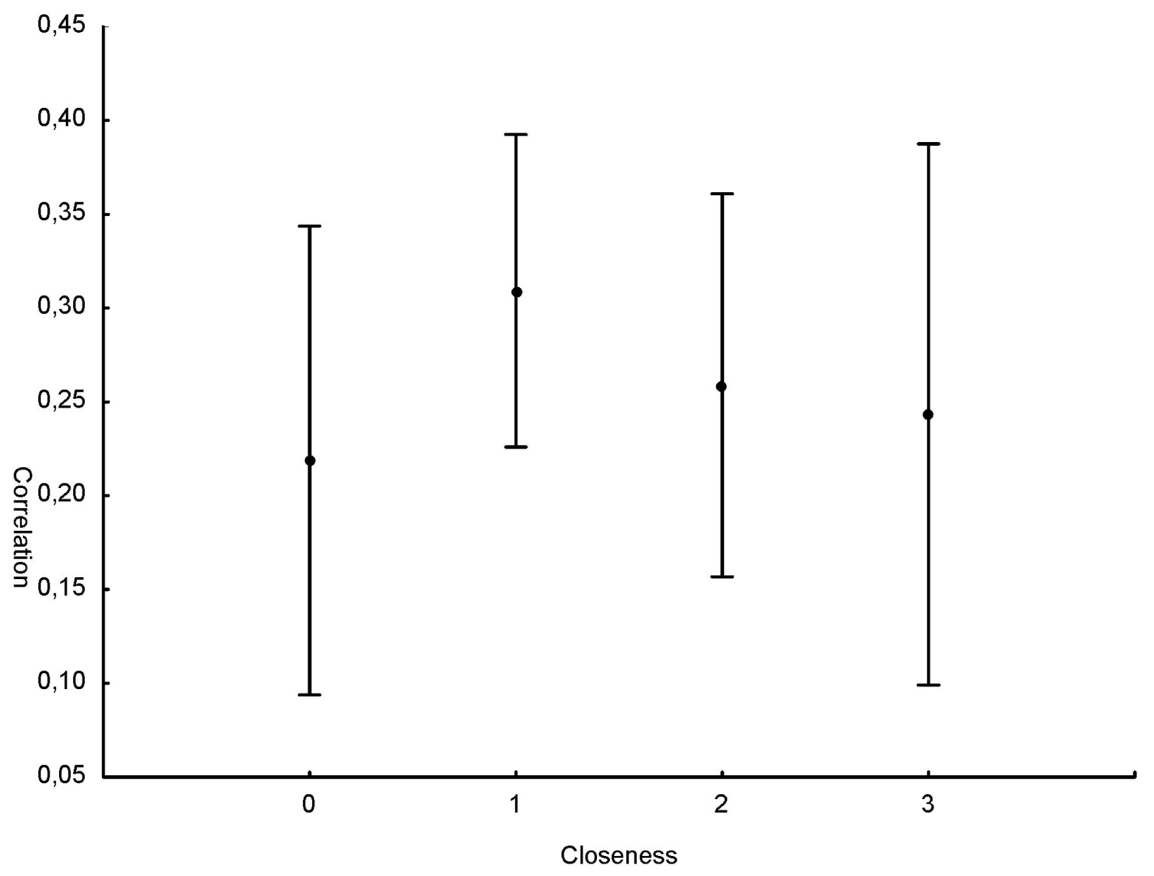

Figure 2. Correlations of the upper crown elements in the genus Equus depending on their closeness in the toothrow: 0 - within the same tooth, 1 - adjacent teeth, 2 - separated by one tooth, 3 - separated by two teeth.

between elements within and among particular upper teeth on average are low and nearly the same $(0.19-0.22)$. In the lower toothrow, the general outlines of the molars are conspicuously more correlated (0.66) as compared to the premolars (0.49). No significance levels of the particular correlation coefficients were estimated because of the small sample size.

Comparison of the averaged correlations between the upper crown elements with respect to their closeness in the toothrow shows the following pattern (Fig. 2). The elements within each tooth are least correlated with each other $(0.22)$. Correlations between the elements of different teeth decrease slowly from the adjacent teeth $(0.31)$ to the most distant ones $(0.24)$. Correlation between the general outlines of the upper and lower teeth is the lowest $(0.17-0.20)$.
Table 3. Correlation coefficients (absolute values) between crown elements of the lower toothrow in the genus Equus.

\begin{tabular}{|l|c|c|c|}
\hline & lo_P3-1 & lo_P4-1 & lo_M1-1 \\
\hline lo_P4-1 & 0.49 & & \\
\hline lo_M1-1 & 0.13 & 0.18 & \\
\hline lo_M2-1 & 0.21 & 0.26 & 0.67 \\
\hline
\end{tabular}

Note: See Table 1 for designations of the crown elements. 

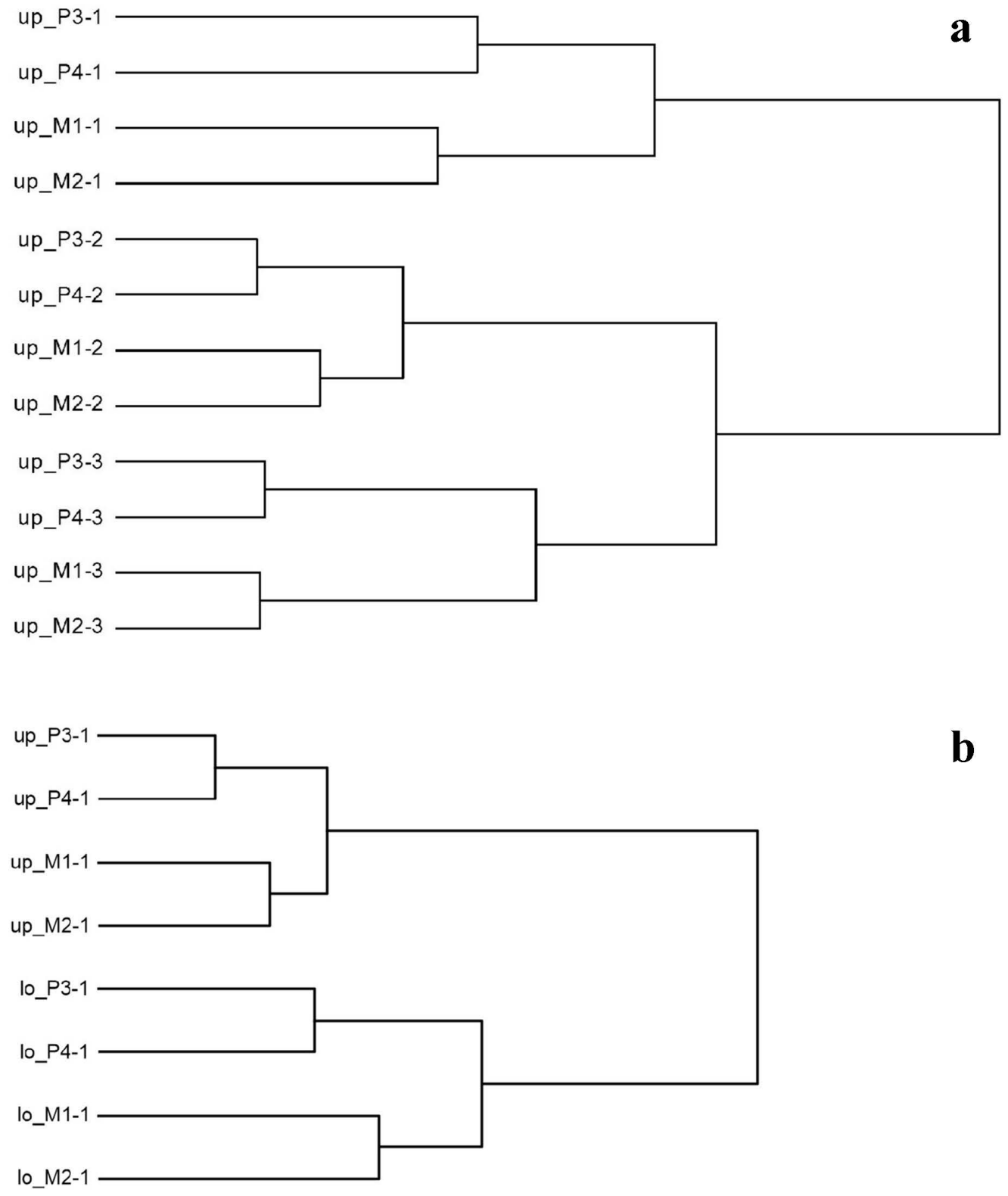

Figure 3. Phenograms illustrating levels of integration of the crown elements of the upper (a) and upper + lower (b) toothrows in the genus Equus. Designations of the crown elements see in Table 1.

Distribution of the upper crown elements on the phenogram according to their mutual correlation reveals the following hierarchy of their grouping (Fig. 3a). First of all, the crown elements of each of the serial homologs are clustered: a) general outlines, b) prefossettes, and c) postfossettes. At higher hierarchical levels, the homologous elements are clustered first within each of the premolar and molar portions of the toothrow, and then throughout the entire toothrow. All these clusters have a very high level of bootstrap support (no less than 98\%) supposing their unambiguous discreteness. The fossettes of premolars and molars are grouped at the next level, with bootstrap support for their joint cluster being only $28 \%$. The general outlines are minimally correlated with the fossettes, so their respective clusters are separated at the highest level of the phenogram.

Clusterization of the general crown outlines of the upper and lower teeth reveals the following hierarchy (Fig. 3b). The crown outlines of the premolar and molar portions within each toothrow are first clustered, with all clusters having high bootstrap support (no less than 97\%). The next level of hierarchy corresponds to joint cluster of the upper and lower toothrows, which are minimally correlated with each other. 
These correlations are explained by significant similarity (sometimes identity) between the homologous crown elements in their transformation patterns. This is evident from the numerical comparison of the relative contributions of landmarks to the total transformations of the respective elements on different teeth (see Rohlf, 1993, on the calculation and meaning of these contributions). Spearman's rank correlation coefficients equal $0.84-0.94$ and $0.60-0.93$ for general outlines in the upper and lower toothrows, respectively; they equal 0.84-0.91 and 0.81-0.90 for upper prefossettes and postfossettes, respectively; they equal $0.32-0.47$ between prefossettes and postfossettes. Visual comparison of the crown elements by most variable portions of their contour lines (Fig. 4) clearly illustrates these numerical estimates.

\section{Discussion}

In the above results, the following main points deserving discussion are to be highlighted:

- correlations are highest between the serial homologous crown elements, namely, between prefossettes, postfossettes, and general outlines, regardless of their position within the upper toothrow;
- correlations between the non-homologous crown elements within the same tooth are noticeably lower;

- correlations between the crown elements within the same (premolar or molar) toothrow portion are higher than between those belonging to different portions;

- correlations between the homologous elements of different teeth in the same toothrow decrease gradually depending on their remoteness;

- correlations between crown elements on the upper and lower teeth are minimal.

On this basis, two levels of the static (in the sense of Klingenberg, 2014) integration of the dental crown elements are clearly distinguished. This strongly supports an initial hypothesis of the existence of several levels of integration in the equine cheek toothrows. Of special importance is that this integration pattern encompasses individually particular crown elements and does not affect the whole teeth as morphological entities. This result confirms indirectly the previously obtained conclusion that the cheek toothrow in the horses is an integrated whole, with particular teeth not representing individualized elements of its structure (Spasskaya \& Pavlinov 2008)

With this, the horse toothrows demonstrate some differentiation patterns presumed by the traditional
P3<smiles>C1CCCCCCCCCCCCCCC1</smiles><smiles>C1CCCCCCCCC1</smiles>

P4<smiles>C1CCCCCCCCCCCCCCCC1</smiles><smiles>C1CCCCCCCC1</smiles>

M1

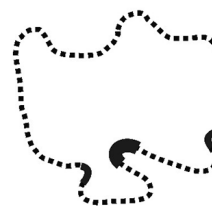<smiles>C1CCCCCCCCC1</smiles>

M2

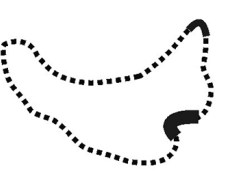

$b$
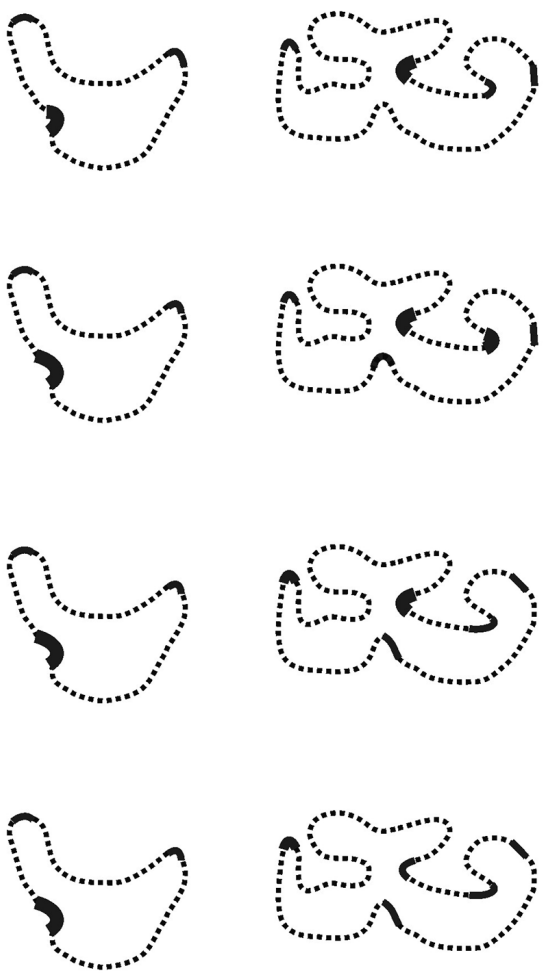

C

Figure 4. Crown elements with the most variable areas of their contour lines indicated by bold lines. Line thickness reflects relative contribution of the respective landmarks to the total transformations of the elements. P3-M2 - teeth; $a$ - upper general outline, $b$ - prefossette, $c$ - postfossette, $d$ - lower general outline. 
ideas about general principles of organization of the dental system in mammals. On the one hand, the crown elements of the premolar and molar portions of both upper and lower toothrows are clearly separated. This differentiation pattern is noteworthy because the P3 and P4 in the horses are strongly molarized, i.e., they are functionally and anatomically very similar to the molars. On the other hand, the dynamics of correlations of the crown elements along the upper toothrow clearly corresponds to the "nearest neighbor rule" according to the concept of morphogenetic (growth) fields (Van Valen, 1965; Gould \& Garwood, 1969; Cochard, 1981). This rule is supposedly explained in part by eruption sequences of the teeth (Gould \& Garwood, 1969; Cochard, 1981; Parner et al., 2002; Klingenberg, 2008a), which is indirectly supported by our findings: premolars erupt later than molars.

The causes of differentiation and integration of the cranial and dental elements in mammals are diverse and complexly interacting (Stock, 2001; Monteiro et al., 2005; Goswami, 2006; Klingenberg, 2008a, 2014; Hallgrímsson et al., 2009; Laffont et al., 2009; GómezRobles \& Polly, 2012; Labonne et al., 2014). So it seems premature to discuss them with respect to the horse dentition taking into account preliminary character of our study based on the limited materials. Nor do our results provide any tough ground for a more detailed analysis of both stability and diversity of the correlation structure of the horse dentition, including the differences between species. At the same time, we would like to draw attention to the following important issues in the research on this structure, albeit very speculative, as well as to the possible prospects for further research of this kind.

Firstly, a very low correlation between upper and lower enamel crown patterns in the horses is to be emphasized. This finding contributes to the controversy observed among the results of similar analyses of the dentition with different types of crown patterns: they indicate that the occluding upper and lower teeth may be either strongly or weakly correlated (i.e., Kurtén, 1953; Cochard, 1981; Pengilly, 1984; Pavlinov et al., 2008; Spasskaya \& Pavlinov, 2008; Laffont et al., 2009; Renaud et al., 2009; Gómez-Robles \& Polly, 2012; Labonne et al., 2014), while non-occluding teeth appeared to be strongly correlated in some cases (Gingerich \& Winkler, 1979). These controversial results indicate that the traditional explanation of the correlation between occluding upper and lower teeth due to their direct interaction supported by their morphogenetic integration may not be universally correct.

Secondly, the peculiar correlation pattern between the basic crown elements seems to have a certain relevance to the problem of modular organization of the equine dentition. According to our findings, most integrated appeared to be the fossettes on different teeth within the toothrow. It is important to notice that this specific integration pattern appeares to be very fine-tuned, with the prefossettes and postfossettes belonging to two different most integrated structures. They evidently correspond to the serial homologous structures realizing the same duplicated developmental programs (on the latter, see Hall, 1995; Young \& Hallgrimsson, 2005). Therefore, it might be reasonable to consider them the elements of two spatially dispersed anatomical (and supposedly developmental) modules, albeit spatially compact structures are usually considered this way (Stock, 2001; Schlosser \& Wagner, 2004; Callebaut \& Rasskin-Gutman, 2005).

Lastly, one of the remarkable and nontrivial features of these two main "modules" identified in the structure of the upper dental crowns is that their elements are fossettes. They are basic functional units of the flattened crown surface of the hypsodont dentition in the advanced Equidae. In the evolution of this family, their anatomical predecessors were the spaces between cones and crests (lophs) on the tooth crowns, which were the main functional units of the buno-lophodont dentition in the archaic equids (Jernvall, 1995; Jernvall et al., 2000; Strömberg, 2006). In ontogeny of the extant horses, cones are non-identifiable and lophs are initially formed, while fossettes appear subsequently with the tooth crown progressive wear (Soana et al., 1999). It is important to emphasize that in the bunodont mammalian dentition, the principal objects of the morphogenetic regulation seem to be the cones and lophs, which are considered traditionally as the minimal elements of the toothrow modular structure (Jernvall, 2000; Stock, 2001). However, as our results showed, in a fully developed hypsodont horse dentition, they were just the fossettes, or rather their enamel layers, that appeared to be the elements of its modular organization. One may speculate that this correlation pattern is the result of an integrated morphogenetic regulation of multiple cones and lophs that have functioned as separate modules in the dentition of archaic equids (C. Barrón-Ortiz, in litt.).

In this regard, if we consider these "dispersed modules" from a point of view of the evo-devo concept, the following key speculative questions come to mind. First, how had this specific fossette modularity emerged in the phylogeny of the horses to have replaced a supposed cone/ridge modularity (which patterns were not studied yet in the primitive equids)? Second, did the fossettes gain their own morphogenetic regulators, at least due to modification of the activity of presumed cones/ridges regulators, or not? And third, how did the evolvability of such "dispersed modules" emerge and change in the course of the equid evolution? All these questions seem to have a certain concern to the general problem of the causes of evolvability of the complex morphological structures (Wagner \& Altenberg, 1996; Schlosser \& Wagner, 2004; Klingenberg, 2005, 2008a; Laubichler \& Maienschein, 2008).

Obviously, getting answers to these and other substantive questions related to the formation of correlation pattern of the equid dentition is not an easy task; it first requests resolving certain technical and methodological problems. Indeed, an examination of the interspecies differences of the those pattern based on an analysis of complete dentitions in the fossil taxa, which are rare to find, would be of prime importance. It is highly desirable 
to trace the dynamics of correlations between tooth crown elements through ontogeny, and there are also very few materials available for this. An appropriate method of the comparable description of various elements (cones, ridges, fossettes) of both generalized and specialized equid dental crown patterns is needed to analyze numerically their correlations. The problematic point is how to describe by the same geometric morphometric method (a) the cones, ridges, and spaces between them on the generalized buno-lophodont crown without fossettes, and (b) the fossettes as successors of those spaces on the hypsodont crown without cones and ridges. The location of separate fragments of the enamel outlines corresponding anatomically to the primitive cones and ridges, with their subsequent direct comparison by correlation analysis, might be a possible solution of this task (C. Barrón-Ortiz, in litt.).

For a possible expanding of this seemingly promising field of the dental research, analyses of other advanced ungulates with different variants of the dental crown patterns should be of great interest. The most attractive in this respect seem to be artiodactyls with their variants of the selenodont dental crown patterns (Prothero \& Foss, 2007; Berkovitz \& Shellis, 2018). They are quite diverse taxonomically, and collection materials on many of them are quite numerous in the museums, so it seems to be not very difficult to obtain interesting and important results. Such a comparison will allow revealing a large-scale dynamics of the correlation structure of the elements of the ungulate toothrows and to discuss its possible evolutionary and ecological causes. On the other hand, it seems important to compare close species within the same genera with respect to their correlation structures to reveal initial stages of the above-considered dynamics.

\section{Conclusions}

A high efficiency of the geometric morphometrics using outline points as a descriptor of the enamel outlines of the dental crowns in the equid family for their comparative study is shown. A combination of EFA, correlation, and cluster analyses provides a good toolkit for the exploration of the levels of integration of the dental crown patterns thus described.

The analysis of the correlation between the tooth crown elements in the genus Equus clearly reveals the following levels of integration of their toothrows: a) the serial homologous elements within each portion (premolar and molar) of the toothrow and b) the same elements across the entire toothrow as a whole. No significant correlations were revealed between different crown elements within a tooth and between upper and lower toothrows.

In general, the cheek toothrow in the genus Equus, at a phenomenological (static) level, seems to represent an integrated morphological structure organized according to the modular principle. In the upper toothrow, the most integrated modular units are the fossettes as elementary serial homologs. Thus, these modules are not spatially compact but dispersed ones.
Correlations between crown elements of different teeth decrease slowly with increase of distances between them along the toothrow. Thus, the "neighbor effect" is expressed in the equid dentition, though rather weakly.

Similar studies of the levels of integration of elements in the specialized dentitions in various groups of ungulates seem to be quite promising. They will make it possible to identify both common and specific patterns of the correlation structure of their dentitions, including its both phylogenetic and ecological conditioning, within the framework of the evo-devo concept.

ACKNOWLEDGEMENTS. The authors are sincerely grateful to Andrea Cardini (Università di Modena e Reggio Emilia, Italy), Andrei Puzachenko (Institute of Geography RAS, Russia), and Miriam Zelditch (University of Michigan, USA) for a useful discussion of some technical points, as well as to Christina I. Barrón-Ortiz (Royal Alberta Museum, Canada), Alessandro Minelli (Università di Padova, Italy), and to an anonymous reviewer for some important comments on the results of our study. The research was conducted as a part of The Governmental Theme no. 121032300105-0 implemented by the Research Zoological Museum at Lomonosov Moscow State University.

\section{References}

Alberdi M.T., Arroyo-Cabrales J., Marín-Leyva A.H. \& Polaco O.J. 2014. Study of Cedral horses and their place in the Mexican Quaternary // Revista Mexicana de Ciencias Geológicas. Vol.31. No.2. P.221-237.

Azzaroli A. 1989. The genus Equus in Europe // Lindsay E.H., Fahlbusch V. \& Mein P. (eds.). European Neogene mammal chronology. New York: Plenum Press. P.339-356.

Barrón-Ortiz C.I., Rodrigues A.T., Theodor J.M., Kooyman B.P., Yang D.Y. \& Speller C.F. 2017. Cheek tooth morphology and ancient mitochondrial DNA of late Pleistocene horses from the western interior of North America: Implications for the taxonomy of North American Late Pleistocene Equus // PLoS ONE. Vol.12. No.8. e0183045.

Berg R.L. 1960. The ecological significance of correlation pleiades // Evolution. Vol.14. No.1. P.171-180.

Berkovitz B.K.B. \& Shellis R.P. 2018. The teeth of mammalian vertebrates. London: Academic Press. 346 p.

Bernor R.L., Cirilli O., Jukar A.M., Potts R., Buskianidze M. \& Rook L. 2019. Evolution of early Equus in Italy, Georgia, the Indian subcontinent, East Africa, and the origins of African zebras // Frontiers in Ecology and Evolution. Vol.7. P.166.

Bolker J.A. 2000. Modularity in development and why it matters to evo-devo // American Zoologist. Vol.40. No.5. P.770-776.

Bonnet E. \& de Peer Y. 2002. Zt: A software tool for simple and partial Mantel tests // Journal of Statistical Softwear. Vol.7. No.10. P.1-12.

Bookstein F.L. 1991. Morphometric tools for landmark data: Geometry and biology. New York: Cambridge University Press. 435 p. 
Bookstein F.L. 1997. Landmark methods for forms without landmarks: Localizing group differences in outline shape // Medical Image Analysis. Vol.1. No.3. P.225-243.

Boulbes N. \& van Asperen E.N. 2019. Biostratigraphy and palaeoecology of European Equus // Frontiers in Ecology and Evolution. Vol.7. P.301.

Bravo-Cuevas V.M., Jiménez-Hidalgo E. \& Priego-Vargas J. 2011. Taxonomía y hábito alimentario de Equus conversidens (Perissodactyla, Equidae) del Pleistoceno Tardío (Rancholabreano) de Hidalgo, centro de México // Revista Mexicana de Ciencias Geológicas. Vol.28. No.1. P.65-82.

Callebaut W. \& Rasskin-Gutman D. 2005. Modularity. Understanding the development and evolution of natural complex systems. Cambridge (MA): The MIT Press. $472 \mathrm{p}$

Cardini A. 2003. The geometry of the marmot (Rodentia: Sciuridae) mandible: Phylogeny and patterns of morphological evolution // Systematic Biology. Vol.52. No.2. P.186-205.

Cheverud J.M. 1982. Phenotypic, genetic, and environmental morphological integration in the cranium // Evolution. Vol.36. No.3. P.499-516.

Cheverud J.M. 1995. Morphological integration in the SaddleBack Tamarin (Saguinus fuscicollis) cranium // The American Naturalist. Vol.145. No.1. P.63-89.

Cheverud J.M., Wagner G.P. \& Dow M.M. 1989. Methods for the comparative analysis of variation patterns // Systematic Zoology. Vol.38. No.3. P.201-213.

Chuang R. \& Bonhomme V. 2019. Rethinking the dental morphological differences between domestic equids // Journal of Archaeological Sciences. Vol.101. No.1. P.140-148

Churcher C.S. 1993. Equus grevyi // Mammalian Species. No.453. P.1-9.

Cochard L.R. 1981. Patterns of size variation and correlation in the dentition of the red colobus monkey (Colobus badius) // American Journal of Physical Anthropology. Vol.54. No.1. P.139-146.

Cucchi T., Mohaseb A., Peigné S., Debue K., Orlando L. \& Mashkour M. 2017. Detecting taxonomic and phylogenetic signals in equid cheek teeth: Towards new palaeontological and archaeological proxies // Royal Society Open Science. No.4. 160997.

Dalquest W.W. \& Dame J.T.H. 1965. The Pleistocene horse, Equus conversidens // American Midland Naturalist. Vol.74. No.2. P.408-417.

Dayan T., Wool D. \& Simberloff D. 2002. Variation and covariation of skulls and teeth: Modern carnivores and the interpretation of fossil mammals // Paleobiology. Vol.28. No.4. P.508-526.

Dyurst U. 1936. [Exterior of the horse]. Moscow-Leningrad: Selkhozgiz. 344 p. [in Russian].

Eisenmann V. 2020. Equidés monodactyles fossiles (Equus, Allohippus, Plesippus, Hippidion). https://vera-eisenmann. com/-equides-monodactyles-fossiles-equus-allohippusplesippus-?lang=en

Ferson S.F., Rohlf F.J. \& Koehn R.K. 1985. Measuring shape variation of two-dimensional outlines // Systematic Zoology. Vol.34. No.1. P.59-68.

Foronova I.V. 2002. Late quaternary equids (genus Equus) of South-western and South-central Siberia // Mashkour M. (ed.). Equids in time and space: Papers in honour of Véra Eisenmann. Oxford: Oxbow Books. P.20-30.

Gidley J.W. 1901. Tooth characters and revision of the North American species of the genus Equus // Bulletin of the American Museum of Natural History. Vol.14. P.91-142.

Gingerich P.D. \& Winkler D.A. 1979. Patterns of variation and correlation in the dentition of the red fox, Vulpes vulpes // Journal of Mammalogy. Vol.60. No.4. P.691-704.

Gómez-Robles A. \& Polly P.D. 2012. Morphological integration in the hominin dentition: evolutionary, developmental, and functional factors // Evolution. Vol.66. No.4. P.1024-1043.

Goswami A. 2006. Morphological integration in the carnivoran skull // Evolution. Vol.60. No.1. P.169-183.

Goswami A. \& Polly P.D. 2010. Methods for studying morphological integration and modularity // The Paleontological Society Papers. Vol.16. P.213-243.

Gould S.J. \& Garwood R.A. 1969. Levels of integration in mammalian dentitions: An analysis of correlations in Nesophontes micrus (Insectivora) and Oryzomys couesi (Rodentia) // Evolution. Vol.23. No.3. P.276-300.

Hall B.K. 1995. Homology and embryonic development // Hecht M.K., Macintyre R.J. \& Clegg M.T. (eds.). Evolutionary Biology. Boston: Springer. P.1-36.

Hallgrímsson B., Jamniczky H., Young N.M., Rolian C., Parsons T.E., Boughner J.C. \& Marcucio R.S. 2009. Deciphering the palimpsest: Studying the relationship between morphological integration and phenotypic covariation // Evolutionary Biology. Vol.36. No.4. P.355-376.

Hammer Ø., Harper D. \& Ryan P.D. 2001. PAST. PAleontological STatistics software package for education and data analysis // Palaeontologia Electronica. Vol.4. No.1. P.1-9.

Hay O.P. 1915. Contributions to the knowledge of the mammals of the Pleistocene of North America // Proceedings of the United States National Museum. Vol.48. No.2086. P.515-575.

Heck L., Wilson L.A.B., Evin A., Stange M. \& SánchezVillagra M.R. 2018. Shape variation and modularity of skull and teeth in domesticated horses and wild equids // Frontiers in Zoology. Vol.15. P.14.

Hibbard C.W. 1953. Equus (Asinus) calobatus Troxell and associated vertebrates from the Pleistocene of Kansas // Transactions of the Kansas Academy of Science. Vol.56. No.1. P.111-126.

Hulbert R.C. 1995. Equus from Leisey Shell Pit La and other Irvingtonian localities from Florida // Bulletin of the Florida Museum of Natural History. Vol.37. No.17. P.553-602.

Jernvall J. 1995. Mammalian molar cusp patterns: Developmental mechanisms of diversity // Acta Zoologica Fennica. Vol.198. P.1-61.

Jernvall J. 2000. Linking development with generation of novelty in mammalian teeth // Proceedings of the National Academy of Sciences. Vol.97. P.2641-2645.

Jernvall J., Hunter J.P. \& Fortelius M. 2000. Trends in the evolution of molar crown types in ungulate mammals: evidence from the Northern Hemisphere // Teaford M.F., Smith M.M. \& Ferguson M.W.J. (eds.). Development, function and evolution of teeth. Cambridge (UK): Cambridge University Press. P.269-281.

Klingenberg C.P. 2005. Developmental constraints, modules and evolvability // Hallgrimsson B. \& Hall B.K. (eds.). 
Variation: A central concept of biology. Oxford: Academic Press. P. 219-247.

Klingenberg C.P. 2008a. Morphological integration and developmental modularity // Annual Review of Ecology, Evolution, and Systematics. Vol.39. P.115-132.

Klingenberg C.P. 2008b. Novelty and "homology-free" morphometrics: What's in a name? // Evolutionary Biology. Vol.35. No.1. P.186-190.

Klingenberg C.P. 2009. Morphometric integration and modularity in configurations of landmarks: Tools for evaluating a priori hypotheses // Evolution \& Development. Vol.11. No.4. P.405-421.

Klingenberg C.P. 2014. Studying morphological integration and modularity at multiple levels: Concepts and analysis // Philosophical Transactions of the Royal Society B: Biological Sciences. Vol.369. No.1649. 20130249.

Kuhl F.P. \& Giardina C.R. 1982. Elliptic Fourier analysis of a closed contour // Computer Graphics and Image Processing. Vol.18. No.3. P.236-258.

Kurtén B. 1953. On the variation and population dynamics of fossil and recent mammal populations // Acta Zoologica Fennica Vol.76. P.1-122.

Kurtén B., 1968. Pleistocene mammals of Europe. Chicago: Aldine. 217 p.

Labonne G., Navarro N., Laffont R., Chateau-Smith C. \& Montuire S. 2014. Developmental integration in a functional unit: Deciphering processes from adult dental morphology // Evolution \& Development. Vol.16. No.4. P.224-232.

Laffont R., Renvoise E., Navarro N., Alibert P. \& Montuirea S. 2009. Morphological modularity and assessment of developmental processes within the vole dental row (Microtus arvalis, Arvicolinae, Rodentia) // Evolution \& Development. Vol.11. No.3. P.302-311.

Laubichler M.D. \& Maienschein J. 2008. Evolving pathways: Key themes in evolutionary developmental biology. New York: Cambridge University Press. 446 p.

Ledevin R., Quéré J.-P. \& Renaud S. 2010. Morphometrics as an insight into processes beyond tooth shape variation in a bank vole population // PLoS ONE. Vol.5. No.11. e15470.

Lyakh A.M. 2019. Analysis of biological shapes on the basis of coordinated coefficients of elliptic Fourier transformation // Science in the South of Russia. Vol.15. No.4. P.63-70

MacFadden B.J. 1993. Fossil horses: Systematics, paleobiology, and evolution of the family Equidae. Cambridge University Press, Cambridge (UK). 384 p.

MacFadden B.J. 2013 Dispersal of Pleistocene Equus (family Equidae) into South America and calibration of GABI 3 based on evidence from Tarija, Bolivia // PLoS ONE. Vol.8. No.3. e59277.

Magwene P.M. 2008. Using correlation proximity graphs to study phenotypic integration // Evolutionary Biology. Vol.35. No.3. P.191-198.

Mitteroecker P. 2009. The developmental basis of variational modularity: Insights from quantitative genetics, morphometrics, and developmental biology // Evolutionary Biology. Vol.36. No.4. P.377-385.

Mitteroecker P. \& Gunz P. 2009. Advances in geometric morphometrics // Evolutionary Biology. Vol.36. No.4. P.235-247.

Monteiro L.R., Bonato V. \& dos Reis S.F. 2005. Evolutionary integration and morphological diversification in complex morphological structures: Mandible shape divergence in spiny rats (Rodentia, Echimyidae) // Evolution \& Development. Vol.7. No.5. P.429-439.

Murren C.J. 2002. Phenotypic integration in plants // Plant Species Biology. Vol.17. No.2-3. P.89-99.

Navarro N., Zararain X. \& Montuire S. 2004. Effects of morphometric descriptor change on statistical classification and morphospaces // Biological Journal of the Linnean Society. Vol.83. No.2. P.243-260.

Olson E.C. \& Miller R.L. 1958. Morphological integration. Chicago: University of Chicago Press. 376 p.

Parner E.T., Heidmann J.M., Kjær I., Væth M. \& Poulsen S. 2002. Biological interpretation of the correlation of emergence times of permanent teeth // Journal of Dental Research. Vol.81. No.7. P.451-454.

Pavlicev M.C., James M. \& Wagner G.P. 2009. Measuring morphological integration using eigenvalue variance // Evolutionary Biology. Vol.36. No.4. P.157-170.

Pavlinov I.Ya. 2011. Morphological disparity: An attempt to widen and to formalize the concept // Pavlinov I.Ya. (ed.). Research in biodiversity: Models and applications. Rejeka: InTech Open. P.341-364.

Pavlinov I.Ya. \& Mikeshina N.G. 2002. [Principles and methods of geometric morphometrics] // Journal of General Biology. Vol.63. No.6. P.473-493. [in Russian, with English summary]

Pavlinov I.Ya., Nanova O.G. \& Lissovsky A.A. 2008a. [Correlation analysis of the structure of the cheek toothrow in the Arctic fox (Alopex lagopus, Canidae)] // Zoological Journal. Vol.87. No.7. P.862-875. [in Russian, with English summary]

Pavlinov I.Ya., Nanova O.G. \& Spasskaya N.N. 2008b. [To exploration of the morphological disparity of the measurable traits of the mammalian skull. 1. On the relation of different forms of the group variation] // Journal of General Biology. Vol.69. No.5. P.453-459. [in Russian, with English summary]

Pengilly D. 1984. Developmental versus functional explanations for patterns of variability and correlation in the dentitions of foxes // Journal of Mammalogy. Vol.65. No.1. P.34-43.

Prothero D.R. \& Foss S.E. 2007. The evolution of artiodactyls. Baltimore: John Hopkins University Press. 384 p.

Renaud S., Pantalacci S., Quéré J.-P., Laudet V. \& Auffrayd J.-C. 2009. Developmental constraints revealed by co-variation within and among molar rows in two murine rodents // Evolution \& Development. Vol.11. No.5. P.590-602.

Rohlf F.J. 1993. Relative warps analysis and example of its application to mosquito wings // Marcus L.F., Bello E. \& Garcia-Valdecasas A. (eds.). Contributions to morphometrics. Madrid: C.S.C.I. P.131-160.

Rohlf F.J. 2017. tpsDig2 ver. 2.31. State University at Stony Brook, New York, NY (program).

Rohlf F.J. 2019. tpsUtil ver. 1.78. State University at Stony Brook, New York, NY (program).

Rostova N.S. 2002. [Correlations, their structure and variability] // Trudy Sanct-Petersburg Soc. Naturalists. Vol.94. No.1. 306 p. [in Russian, with English summary]

Schlosser G. \& Wagner G.P. 2004. Modularity in development and evolution. Chicago: University of Chicago Press. $600 \mathrm{p}$. 
Seetah K., Cardini A. \& Barker G. 2016. A "long-fuse domestication" of the horse? Tooth shape suggests explosive change in modern breeds compared with extinct populations and living Przewalski's horses // The Holocene. Vol.26. No.8. P.1326-1333.

Soana S., Gnudi G. \& Bertoni G. 1999. The teeth of the horse: Evolution and anatomo-morphological and radiographic study of their development in the foetus // Anatomia, Histologia, Embryologia. Vol.28. No.5-6. P.273-280.

Spasskaya N.N. \& Pavlinov I.Ya. 2008. [Variation and correlations structure of the cheek toothrow in the Przewalski's horse (Equus przewalskii; Mammalia: Equidae)] // Bulletin of Moscow Society of Naturalists. Biological series. Vol.113. No.2. P.3-13. [in Russian, with English summary]

StatSoft Inc. 2014. Statistica (Data Analysis Software System), Version 12 (program).

Stock D.W. 2001. The genetic basis of modularity in the development and evolution of the vertebrate dentition // Philosophical Transactions of the Royal Society B: Biological Sciences. Vol.356. No.1414. P.1633-1653.
Suna B., Deng T. \& Liu Y. 2019. Early Pleistocene Equus (Equidae, Perissodactyla) from Andersson Loc. 32 in Qixian, Shanxi, China // Historical Biology. Vol.31. No.2. P.211-222.

Van Valen L. 1965. The study of morphological integration // Evolution. Vol.19. No.3. P.347-349.

Vasil'ev A.G., Vasil'eva I.A. \& Shkurihin A.O. 2018. [Geometric morphometry: from theory to practice]. Moscow: KMK Scientific Press. 471 p. [in Russian]

Wagner G.P. \& Altenberg L. 1996. Perspective: Complex adaptations and the evolution of evolvability // Evolution. Vol.50. No.3. P.967-976.

Young N.M. \& Hallgrimsson B. 2005. Serial homology and the evolution of mammalian limb covariation structure // Evolution. Vol.59. No.12. P.2691-2704.

Zelditch M.L. \& Swiderski D.L., Sheets H.D. 2012. Geometric morphometrics for biologists: A primer. 2nd ed. Amsterdam: Elsevier. 443 p.

Zelditch M.L., Wood, A.R. \& Swiderski D.L. 2009. Building developmental integration into functional systems: Function-induced integration of mandibular shape // Evolutionary Biology. Vol.36. No.1. P.71-87.

Appendix. Materials (number of toothrows per species) studied in this project

\begin{tabular}{|c|c|c|c|c|}
\hline Species (listed alphabetically) & $\begin{array}{l}\text { Upper } \\
\text { toothrow }\end{array}$ & $\begin{array}{l}\text { Lower } \\
\text { toothrow }\end{array}$ & Subgeneric allocation & Sources of specimens \& images \\
\hline asinus & 1 & 2 & Asinus & ZMMU \\
\hline caballus & 2 & 1 & Equus & ZMMU \\
\hline calobatus & 1 & 1 & $?$ & Hibbard (1953) \\
\hline complicatus & 1 & & Equus & Gidley (1901) \\
\hline conversidens & 1 & 3 & Amerhippus? & $\begin{array}{l}\text { Dalquest, Dame (1965); } \\
\text { Bravo-Cuevaset et al. (2011); } \\
\text { Eisenmann (2020) }\end{array}$ \\
\hline fransici & 1 & & Amerhippus? & Hay $(1915)$ \\
\hline gallicus & & 2 & Equus & Foronova $(2006)$ \\
\hline granatensis & 1 & 1 & Sussemionus & Boulbes, van Asperen (2019) \\
\hline grevyi & 3 & 3 & Hippotigris & $\begin{array}{l}\text { Churcher (1993); } \\
\text { ZMMU }\end{array}$ \\
\hline hatchei & 1 & 1 & Equus & Hay (1915) \\
\hline hemionus & 2 & 4 & Asinus & ZMMU \\
\hline hydruntinus & 1 & & Asinus & Kurtén (1968) \\
\hline insulatus & 1 & 1 & Amerhippus & MacFadden (2013) \\
\hline kiang & 1 & 2 & Asinus & ZMMU \\
\hline lassalei & & 1 & $?$ & Eisenmann (2020) \\
\hline mexicanus & & 1 & Equus? & Alberdi (2014) \\
\hline mosbachensis & 2 & 1 & Equus & $\begin{array}{l}\text { Azzaroli (1989); } \\
\text { Foronova (2002); } \\
\text { Boulbes \& van Asperen (2019) }\end{array}$ \\
\hline nevadensis & 1 & & Amerhippus & Eisenmann (2020) \\
\hline niobrarensis & 1 & & Equus & Eisenmann (2020) \\
\hline occidentelis & 2 & & Amerhippus & Eisenmann (2020) \\
\hline pectinatus & 1 & & $?$ & Gidley (1901) \\
\hline podolicus & 1 & & Equus & Drygant 2016 \\
\hline przewalskii & 3 & 3 & Equus & ZMMU \\
\hline qingyangensis & & 1 & Plesippus & Sun et al. (2017) \\
\hline scotti & 2 & 2 & Equus & Hulbert (1995) \\
\hline semiplicatus & 1 & & $?$ & Eisenmann (2020) \\
\hline simplicidens & & 1 & Plesippus & Bernor et al. (2019) \\
\hline tyvericus & 2 & & Equus & Drygant (2016) \\
\hline zebra & 1 & & Hippotigris & ZMMU \\
\hline
\end{tabular}

